\title{
CADASTRAMENTO BACTERIOLÓGICO ANTITUBERCULOSE: ESTUDO PRELIMINAR PARA SUA IMPLANTAÇÃO EM UMA COMUNIDADE DO ESTADO DE SÃO PAULO (BRASIL)
}

ARANTES, G. R. \& TRIvelatto, L. B. - Cadastramento bacteriológico antituberculose: estudo preliminar para sua implantaçāo em uma comunidade do Estado de São Paulo (Brasil). Rev. Saúde públ., S. Paulo, $10: 167-76,1976$.

RESUMO: Foi elaborada esta pesquisa para determinar a necessidade de se conhecer certas características da comunidade, antes de se implantar a busca de casos pelo cadastramento bacteriológico. Foram estudadas 30.885 pessoas residentes com 15 anos e mais de idade, que se matricularam no Centro de Saúde de Ribeiräo Preto, SP (Brasil), durante 12 meses consecutivos. Houve boa aceitaçōo do cadastramento embora tenha ocorrido uma significativa proporção de falsos assintomáticos. A incidência de doentes entre os sintomáticos examinados foi de $5,3 \%$ e a ocorréncia de casos positivos apenas à cultura chegou a 35\%. Estimou-se que a prevalência de sintomáticos respiratórios na população de referência seja no minimo igual a 4,3\%.

UNITERMos: Cadastramento bacteriológico. Sintomáticos respiratórios. Falsos assintomáticos.

\section{NTRODUCAO}

Diante da inviabilidade de expandir a busca de casos de tuberculose através do cadastro torácico ${ }^{1}$, surge com alternativa óbvia o cadastramento bacteriológico. A implementação dessa atividade requer o prévio conhecimento de alguns parâmetros: comportamento da população face à oferta desse serviço; demanda esperada de sintomáticos às unidades sanitárias; estimativa de casos entre os mesmos; proporção esperada de casos positivos apenas à cultura.
Pouco se sabe a respeito desses parâmetros, alguns dos quais indispensáveis para programar essa forma de rastreamento da doença. Embora possam ser usados informes disponíveis em áreas semelhantes, por sinal escassos, é preferível contar com dados próprios uma vez que os mesmos estão sujeitos a influências epidemiológicas e culturais.

A presente investigação foi planejada com o objetivo de estudar algumas dessas variáveis, em município sede de $\mathrm{Di}$ -

* Da 6. Divisão Regional de Saúde (Ribeirão Preto) da Coordenadoria de Saúde da Comunidade. Secretaria da Saúde do Estado de São Paulo - Rua Minas, 895 - Ribeíão Preto, SP - Brasil.

* Do Instituto Adolfo Lutz (Ribeirão Preto) da Coordenadoria de Servicos Técnicos Especlalizados. Secretaria da Saúde do Estado de São Paulo - Ribeirão Preto, SP - Brasil. 
ARANTES, G. R. \& TRIVELLATO, L. B. - Cadastramento bacteriológico antituberculose: estudo preliminar para sua implantação em uma comunidade do Estado de São Paulo (Brasil). Rev. Saúde públ., S. Paulo, 10:167-76, 1976.

visão Regional de Saúde ${ }^{10}$, com vistas à integração do programa antituberculose nas unidades sanitárias da região, de acordo com plano previamente aprovado ${ }^{1}$.

\section{MATERIAL E METODOS}

0 município de Ribeirão Preto está localizado na região fisiográfica de Ribeirão Preto ${ }^{\circ}$, Estado de São Paulo, região sudeste do Brasil. A população de referência em $1 / 9 / 73$, isto é, com 15 anos e mais de idade, foi estimada em 154.023 pessoas (método aritmético). A população de estudo foi constituída pelas pessoas residentes com 15 anos ou mais de idade que se matricularam entre $10^{\circ}$ de maio de 1973 e 30 de abril de 1974 no ex-Dispensário de Tuberculose, recentemente incorporado ao Centro de Saúde polivalente. $\mathrm{Na}$ ficha de matrícula, entre outros dados, anotava-se: a condição de consultante (pessoas que procuravam a clínica tisio-pneumológica espontaneamente ou encaminhadas por outras fontes de assistência médica); o comunicante (cohabitante com tuberculoso até um ano após alta ou óbito) ou certificado (com fim de obter ou revalidar carteira ou atestado de saúde). Indagava-se ainda sobre a existência e duração de tosse e/ou expectoração. Em seguida à matrícula as pessoas eram abreugrafadas e submetidas a um teste tuberculínico padronizado ${ }^{5}$; os sintomáticos respiratórios eram orientados para colher escarro no domicílio segundo as normas vigentes ${ }^{4}$. 0 material colhido em recipiente descartável apropriado, era então encaminhado ao Laboratório de Bacteriologia de Tuberculose do Instituto Adolfo Lutz e submetido a exame bacteriológico segundo método descrito anteriormente ${ }^{4,11}$.

Ao todo foram matriculadas 32.225 pessoas tendo sido incluídas na população de estudo $30.885(95,8 \%)$ que completaram o teste tuberculínico; destas, $1.085(3,4 \%)$ forneceram escarro suficiente para a execução do exame bacteriológico.

A composição etária da população de estudo, bem como a distribuição da mesma segundo as categorias de matrícula, podem ser vistas nas Tabelas 1 e 2 .

TABELA 1

Composição etária da demanda da população em estudo, por sexo. Centro de Saúde de Ribeirão Preto, 1973/1974

\begin{tabular}{|c|c|c|c|c|c|c|}
\hline \multirow{2}{*}{$\begin{array}{c}\text { Grupos etários } \\
\text { (anos) }\end{array}$} & \multicolumn{2}{|c|}{ Sexo masculino } & \multicolumn{2}{|c|}{ Sexo feminino } & \multicolumn{2}{|c|}{ Ambos os sexos } \\
\hline & N.o & $\%$ & N.o & $\%$ & N.o & $\%$ \\
\hline 15 a 19 & $\mathbf{5 . 5 8 8}$ & 30,1 & 4.032 & 32,7 & 9.620 & 31,1 \\
\hline 20 a 29 & 6.300 & 34,0 & 4.569 & 37,1 & 10.869 & 35,2 \\
\hline 30 a 39 & 3.288 & 17,7 & 1.975 & 16,0 & 5.263 & 17,0 \\
\hline 40 a 49 & 2.008 & 10,8 & 1.075 & 8,7 & 3.083 & 10,0 \\
\hline 50 a 59 & 963 & 5,2 & 452 & 3,7 & 1.415 & 4,6 \\
\hline 60 e + & 407 & 2,2 & 228 & 1,8 & 635 & 2,1 \\
\hline Total & 18.554 & 100,0 & 12.331 & 100,0 & 30.885 & 100,0 \\
\hline
\end{tabular}


ARANTES, G. R. \& TRIVELLATO, L. B. - Cadastramento bacteriológico antituberculose: estudo preliminar para sua implantacão em uma comunidade do Estado de São Paulo (Brasil). Rev. Salide públ., S. Paulo, 10:167-76, 1976.

\section{RESULTADOS}

Das 30.885 pessoas incluídas na população de estudo. $1.226\left(4 C_{C}\right)$ responderam afirmativamente à pergunta sobre expectoração (sintomáticos confessos) ; entre as 1.340 pessoas matriculadas, porém não incluídas no estudo. a proporção de sintomáticos foi semelhante $(3.8 \%$ ). Na Tabela 3 é apresentada a distribuição dos sintomáticos segundo a duração dos sintomas.
Cerca de 558 pessoas $\left(1.8 C_{c}^{c} c\right.$ da demanda) tireram suas abreugrafias interpretadas como anormais e por isso foram avaliadas clinicamente, Entre elas, 380 haviam negado expectoração ao se matricularem, porém $153(27 \% \mathrm{c})$. posteriormente, referiram presença da mesma e trouxeram escarro para ser examinado (sintomáticos não confessos ou falsos assintomáticos). Assim. os sintomáticos na demanda foram $1.379\left(4.5^{c} c\right)$ e ao todo

TA B E L A 2

Composicão da população em estudo, por sexo, quanto à categoria de matricula. Ribeirão Preto, $1973 / 1974$

\begin{tabular}{|c|c|c|c|c|c|c|c|c|}
\hline \multirow{3}{*}{ Sexo } & \multicolumn{6}{|c|}{ Categoria de matricula } & \multirow{2}{*}{\multicolumn{2}{|c|}{ Total }} \\
\hline & \multicolumn{2}{|c|}{ Consultantes } & \multicolumn{2}{|c|}{$\begin{array}{l}\text { Certificado } \\
\text { de saúde }\end{array}$} & \multicolumn{2}{|c|}{ Comunicantes } & & \\
\hline & N. 0 & $\%$ & N.o & $\%$ & $N . \circ$ & $\%$ & N. $\circ$ & $\%$ \\
\hline Masculino & 1.849 & 10,0 & 16.606 & 89,5 & 99 & 0,5 & 18.554 & 100,0 \\
\hline Feminino & 2.306 & 18,7 & 9.805 & 79,5 & 220 & 1,8 & 12.331 & 100,0 \\
\hline Total & 4.155 & 13,5 & 26.411 & 85,5 & 319 & 1,0 & 30.885 & 100,0 \\
\hline
\end{tabular}

TABELA 3

Sintomáticos confessos segundo a duracão dos sintomas. Grupos etârios de 15 anos ou mais matriculados no Centro de Saúde de Ribeirão Preto, 1973/1971

\begin{tabular}{|c|c|c|c|c|c|c|}
\hline \multirow{2}{*}{$\begin{array}{l}\text { Durasão dos } \\
\text { sintomas } \\
\text { (em dias) }\end{array}$} & \multicolumn{2}{|c|}{ Trouxeram escarro } & \multicolumn{2}{|c|}{ Nāo trouxeram escarro } & \multicolumn{2}{|c|}{ Total } \\
\hline & Suficiente & Insuficiente & $\begin{array}{l}\text { Porque os } \\
\text { sintomas } \\
\text { regrediram }\end{array}$ & $\begin{array}{c}\text { Nāo } \\
\text { justificaram }\end{array}$ & $\Lambda^{r} \cdot{ }^{0}$ & $\%$ \\
\hline Menos de 15 & 382 & 21 & 87 & 33 & 523 & 42.7 \\
\hline $1 \tilde{5}$ a 30 & 212 & 8 & 39 & 22 & 281 & 22,9 \\
\hline 30 a 60 & 111 & 2 & 13 & 7 & 133 & 10,8 \\
\hline Mais de 60 & 227 & 13 & 32 & 17 & 289 & 23,6 \\
\hline Total & 932 & 44 & 171 & 79 & 1.226 & 100,0 \\
\hline
\end{tabular}


ARANTES, G. R. \& TRIVELlato. L B. - Cadastramento bacteriológico antituberculose: estudo preliminar para sua implantacão em uma comunidade do Estado de São Paulo (Brasill. Ret. Salude plibl., S. Paulo, 10:167-76. 1976.

realizaram-se exames de escarros prosenientes de 1.085 pessoas $179 \%_{C}$ dos sintomáticos). Nas Tabelas 4 e 5 aparece a distribuição dos sintomátiticos (confessos e nãol segundo a categoria de matricula $\rightarrow$ a idade. respectivamente. A duraçāo dos sintomas em função da categoria de matrícula pode ser vista na Tabela 6.

A positividade dos exames bacteriológicos segundo a duração dos sintomas. categoria de matrícula e idade é apresentada nas Tabelas 7.8.9 10 .

T A B E L A 4

Sintomáticos confessos e não confessos. segundo a categoria de matricula Centro de Saúde de Ribeirão Preto, 1973/1974

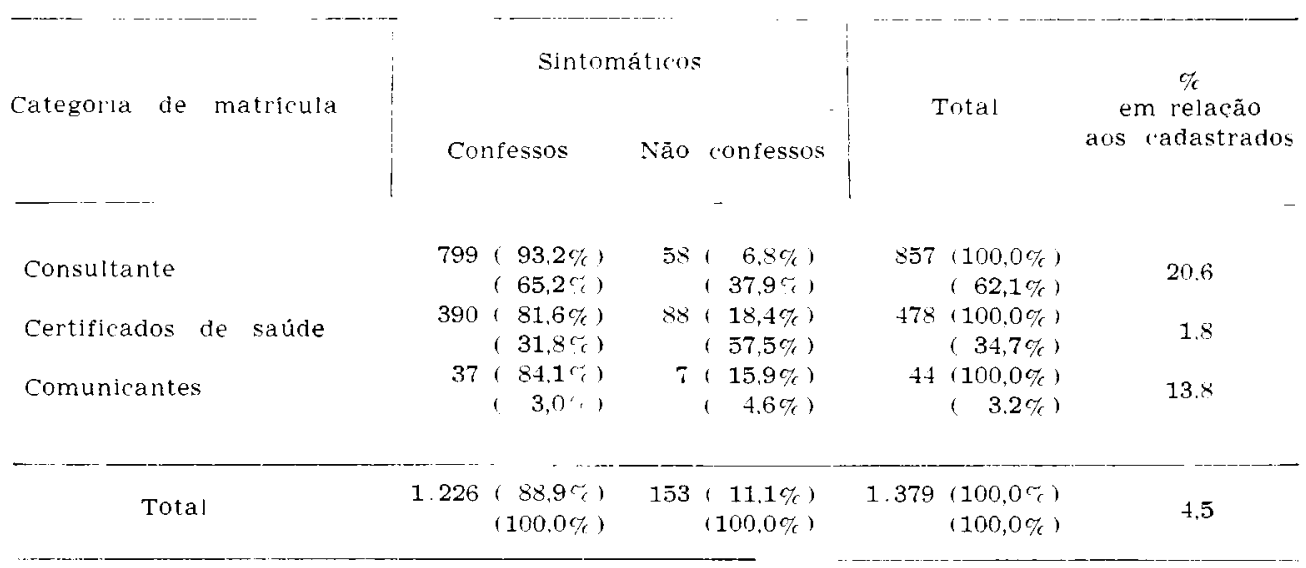

TABELA 5

Sintomáticos confessos e nāo confessos segundo a idade. Centro de Saúde de Ribeirão Preto, $1973 / 1974$

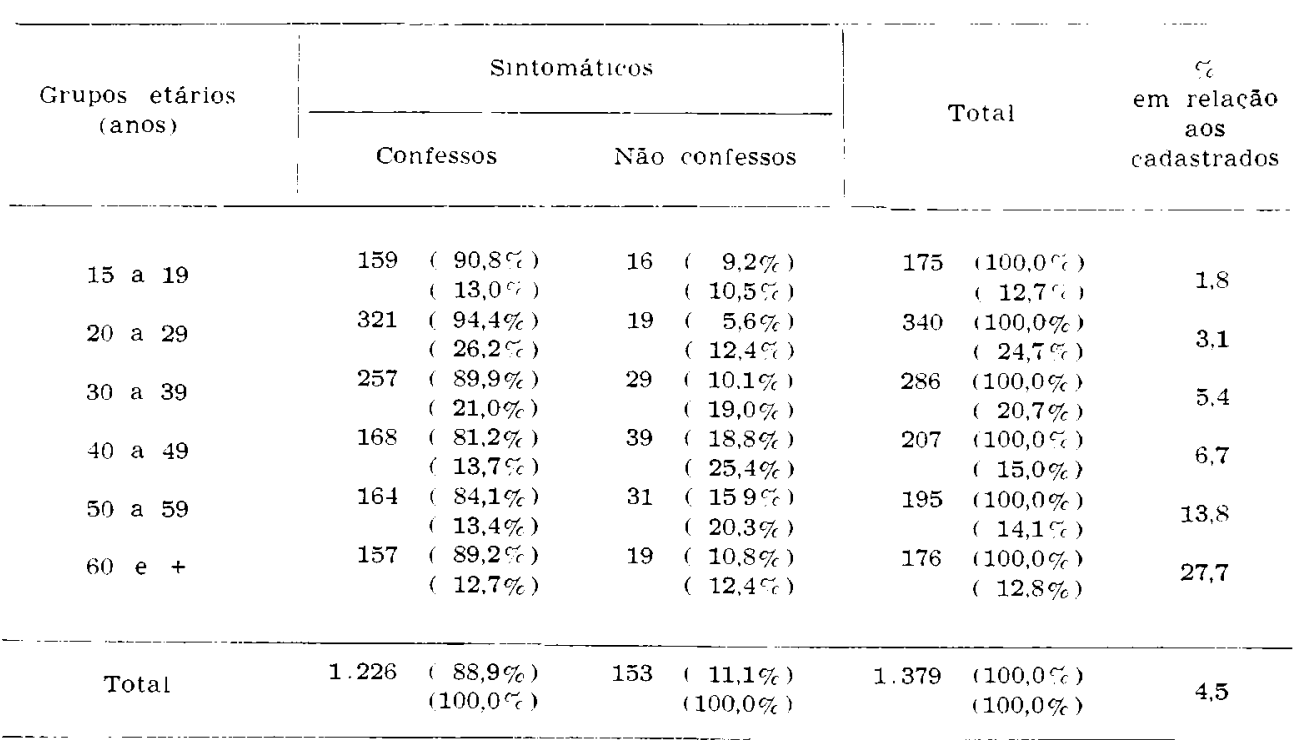


ARANTES, G. R. \& TRIVELLATO, L. B. - Cadastramento bacteriológico antituberculose:
estudo preliminar para sua implantaçáo em uma comunidade do Estado de São Paulo
(Brasil). Rev. Saúde públ., S. Paulo, 10:167-76, 1976.

T A B E L A 6

Duraçăo dos sintomas segundo a categoria de matricula. Centro de Saúde de Ribeirăo Preto, 1973/1974

\begin{tabular}{|c|c|c|c|c|c|c|c|c|c|c|c|c|}
\hline \multirow{3}{*}{$\begin{array}{l}\text { Categorla } \\
\text { de } \\
\text { matricula }\end{array}$} & \multicolumn{3}{|c|}{ Duraçāo } & \multicolumn{5}{|c|}{ os sintomas (em dias) } & \multirow{2}{*}{\multicolumn{2}{|c|}{$\begin{array}{l}\text { Falsos as- } \\
\text { sintomátícos }\end{array}$}} & \multirow{2}{*}{\multicolumn{2}{|c|}{ Total }} \\
\hline & \multicolumn{2}{|c|}{ Menos de 15} & \multirow{2}{*}{$\frac{15}{N .0}$} & \multirow{2}{*}{$\frac{30}{\%}$} & \multirow{2}{*}{$\frac{30}{\text { N.0 }}$} & \multirow{2}{*}{$\frac{60}{\%}$} & \multicolumn{2}{|c|}{$60 \mathrm{e}+$} & & & & \\
\hline & N.o & $\%$ & & & & & N.* & $\%$ & N.u & $\%$ & N." & $\%$ \\
\hline Consultantes & 304 & 35,4 & 208 & 24,3 & 99 & 11,6 & 188 & 21,9 & 58 & 6,8 & 857 & 100,0 \\
\hline Certificados & 204 & 42,7 & 68 & 14,2 & 28 & 5,9 & 90 & 18,8 & 88 & 18,4 & 478 & 100,0 \\
\hline Comunicantes & 15 & 34,1 & 5 & 11,4 & 6 & 13,6 & 11 & 25.0 & $\tau$ & 15,9 & 44 & 100,0 \\
\hline Total & 523 & 37,9 & 281 & 20,4 & 133 & 9,6 & 289 & 21,0 & 153 & 11,1 & 1.379 & 100. \\
\hline
\end{tabular}

TABELA 7

Exames bacteriológicos positivos segundo a duração dos sintomas, ambos os sexos. Centro de Saúde de Ribelrāo Preto, 1973/1974

\begin{tabular}{|c|c|c|c|c|c|c|}
\hline \multirow{2}{*}{$\begin{array}{l}\text { Duraçāo dos } \\
\text { sintomas } \\
\text { (dias) }\end{array}$} & \multicolumn{2}{|c|}{ Escarros examinados } & \multicolumn{2}{|c|}{ Baciloscopias positivas } & \multicolumn{2}{|c|}{ Culturas positivas } \\
\hline & N.0 & $\%$ & N." & $\%$ & N.o & $\%$ \\
\hline Menos de 15 & 382 & 35,2 & 8 & 2,1 & 13 & 3,4 \\
\hline 15 a 30 & 212 & 19,5 & 7 & 3,3 & 13 & 6,1 \\
\hline 30 a 60 & 111 & 10,2 & 3 & 2,7 & 3 & 2,7 \\
\hline $60 \mathrm{e}+$ & 227 & 20,9 & 9 & 3,9 & 13 & 5,7 \\
\hline "Assintomáticos" & 153 & 14,2 & 10 & 6,5 & 15 & 9,8 \\
\hline Total & 1.085 & 100,0 & 37 & 3,4 & 57 & 5,3 \\
\hline
\end{tabular}

T A BELA 8

Baciloscopla semi-quantitativa $(\mathrm{em}+)$ segundo a duração dos sintomas (em dias) em pacientes tuberculosos diagnosticados no Centro de Saúde de Ribeirão Preto, 1973/1974

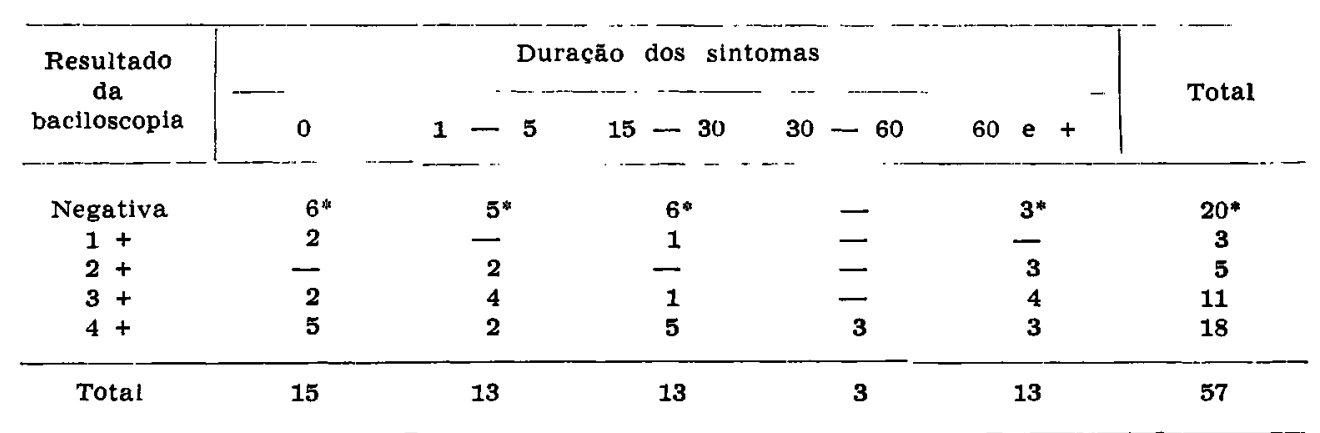

- Positivos apenas a cultura. 
ARANTES, G. R. \& TRIVELLATO, L. B. - Cadastramento bacteriológico antituberculose: estudo preliminar para sua implantação em uma comunidade do Estado de São Paulo (Brasil). Rev. Saúde públ., S. Paulo, 10:167-76, 1976.

Finalmente pode-se observar na Tabela 11 a positividade dos exames bacteriológicos conforme a reatividade tuberculínica.

\section{DISCUSSA O}

Entre as 1.226 pessoas que declararam ter tosse e expectoração apenas 79 $(6,4 \%)$ deixaram de trazer escarro para exame sem qualquer justificativa; do ma- terial recebido $95 \%$ foi satisfatório. Ambos os fatos parecem refletir boa aceitação do cadastramento bacteriológico.

A população de estudo não foi uma amostra casual da população de referência. Considerando, entretanto, que todos os bairros da cidade se fizeram representar em proporção idêntica à sua participação na população total ${ }^{2}$; que todos os grupos etários estavam representados; e que possiveis influências estacionais foram cap-

TABELA 9

Positividade dos escarros examinados por grupos etários, ambos os sexos.

Centro de Saúde de Ribeirão Preto, 1973/1974

\begin{tabular}{|c|c|c|c|c|c|c|}
\hline \multirow[b]{2}{*}{$\begin{array}{c}\text { Grupos etários } \\
\text { (anos) }\end{array}$} & \multirow[b]{2}{*}{$\begin{array}{c}\text { Total de } \\
\text { cadastrados }\end{array}$} & \multirow[b]{2}{*}{$\begin{array}{c}\text { Escarros } \\
\text { examinados }\end{array}$} & \multicolumn{2}{|c|}{ Exames positivos } & \multicolumn{2}{|c|}{ Positividade em relação } \\
\hline & & & N.o & $\%$ & $\begin{array}{c}\text { Aos } \\
\text { escarros } \\
\text { examinados } \\
\%\end{array}$ & $\begin{array}{c}\text { Aos } \\
\text { cadastrados } \\
\% 0\end{array}$ \\
\hline 15 a 19 & 9.620 & 126 & 6 & 10,5 & 4,8 & 0,6 \\
\hline 20 a 29 & 10.869 & 244 & 14 & 24,5 & 5,7 & 1,3 \\
\hline 30 a 39 & 5.263 & 228 & 12 & 21,0 & 5,3 & 2,3 \\
\hline 40 a 49 & 3.083 & 174 & 12 & 21,0 & 6,9 & 3,9 \\
\hline 50 a 59 & 1.415 & 165 & 9 & 15,8 & 5,5 & 6,4 \\
\hline $60 \mathrm{e}+$ & 635 & 148 & 4 & 7,2 & 2,7 & 6,3 \\
\hline Total & 30.885 & 1.085 & 57 & 100,0 & 5,3 & 1,8 \\
\hline
\end{tabular}

TABELA 10

Positividade dos escarros examinados por categoria de matricula, ambos os sexos. Centro de Saúde de Ribeirão Preto, 1973/1974

\begin{tabular}{|c|c|c|c|c|c|c|}
\hline \multirow{2}{*}{ Categoria de matricula } & \multirow{2}{*}{$\begin{array}{c}\text { Total de } \\
\text { cadastrados }\end{array}$} & \multirow{2}{*}{$\begin{array}{c}\text { Escarros } \\
\text { examinados }\end{array}$} & \multicolumn{2}{|c|}{$\begin{array}{l}\text { Exames } \\
\text { positivos }\end{array}$} & \multicolumn{2}{|c|}{ Positividade em relaçáo } \\
\hline & & & N. ${ }^{\circ}$ & $\%$ & $\begin{array}{c}\text { escarros } \\
\text { examinados } \\
\%\end{array}$ & $\begin{array}{c}\text { Aos } \\
\text { cadastrados } \\
\% 0\end{array}$ \\
\hline Consultantes & 4.155 & 696 & 51 & 89,5 & 7,3 & 12,3 \\
\hline Certificados de saúde & 26.411 & 354 & 4 & 7,0 & 1,1 & $0, \mathbf{1 5}$ \\
\hline Comunicantes & 319 & 35 & 2 & 3,5 & 5,7 & 6,3 \\
\hline Total & 30.885 & 1.085 & 57 & 100,0 & 5,3 & 1,8 \\
\hline
\end{tabular}


ARANTES, G. R. \& TRIVELLATO, L. B. - Cadastramento bacteriológico antituberculose: estudo preliminar para sua implantação em uma comunidade do Estado de São Paulo (Brasil). Rev. Saúde pübl., S. Paulo, 10:167-76, 1976.

\section{TABELA 11}

Exames bacteriológicos realizados segundo o resultado do teste tuberculínico e positividade por mil cadastrados, ambos os sexos. Centro de Saúde de Ribeirăo Preto, 1973/1974

\begin{tabular}{|c|c|c|c|c|c|c|}
\hline \multirow{2}{*}{$\begin{array}{l}\text { Resultado do teste } \\
\text { tuberculínico }\end{array}$} & \multirow{2}{*}{$\begin{array}{c}\text { Total de } \\
\text { cadastrados }\end{array}$} & \multirow{2}{*}{$\begin{array}{l}\text { Exames } \\
\text { realizados }\end{array}$} & \multicolumn{2}{|c|}{$\begin{array}{l}\text { Baciloscopias } \\
\text { positivas }\end{array}$} & \multicolumn{2}{|c|}{$\begin{array}{l}\text { Culturas } \\
\text { positivas }\end{array}$} \\
\hline & & & N. 0 & $\%$ & $\mathrm{~N} .0$ & $\%_{0}$ \\
\hline $\begin{array}{l}\text { Não reatores }(0 \text { a } 4 \mathrm{~mm}) \\
\text { Reatores }(5 \mathrm{~mm} \text { ou }+)\end{array}$ & $\begin{array}{l}18.883 \\
11.998\end{array}$ & $\begin{array}{l}\mathbf{5 2 6} \\
\mathbf{5 5 5}\end{array}$ & $\begin{array}{r}0 \\
33\end{array}$ & $\begin{array}{l}0,0 \\
2,8\end{array}$ & $\begin{array}{r}1 \\
52\end{array}$ & $\begin{array}{l}0,06 \\
4,4\end{array}$ \\
\hline Total & $30.881^{*}$ & 1.081 & 33 & 1,1 & $53^{*}$ & 1,8 \\
\hline
\end{tabular}

* Não incluídos 4 doentes sem teste tuberculínico.

tadas no decorrer dos 12 meses, seria possível estimar a prevalência de sintomáticos na comunidade, a partir dos resultados obtidos na demanda?

Houve $1.226(4 \%)$ sintomáticos confessos porém $153(0,5 \%)$ dos que se declararam assintomáticos posteriormente revelaram ter tosse e expectoração. 0 valor predictivo da resposta positiva ${ }^{12}$, isto é, a probabilidade de uma pessoa da população ter os sintomas dado que a resposta inicial tenha sido afirmativa, foi

$$
\text { igual a } \frac{1.226-79}{1.226} \text { ou } 93,6 \% \text {. }
$$

Em contrapartida, a probabilidade de que as pessoas que responderam negativamente não tenham os sintomas (valor predictivo negativo ${ }^{12}$ ) não foi estimada porque só se pôde conferir as respostas de 558 cujas abreugrafias foram anormais e por isso não representativas das demais. Sabendo-se entretanto que houve $1,8 \%$ de anormais à abreugrafia, entre os quais $27 \%$ de falsos assintomáticos, foi possível estimar em 0,5 da demanda o contingente de sintomáticos não confessos $(27 \%$ de $1,8 \%$ igual a $0,5 \%$ ).

Como os sintomáticos confessos foram estimados em $3,8 \% \quad(94 \%$ de $4 \%$ igual a $3,8 \%$ ), o contingente total de sintomá- ticos na demanda seria no mínimo de $4,3 \%(3,8+0,5 \%)$.

Aplicado à população de referência (154.023 habitantes com 15 e mais anos de idade) teríamos uma prevalência de 6.623 sintomáticos respiratórios durante o ano em pauta, dos quais apenas 857 (13\%) procuraram atendimento médico. Estudos sociológicos planejados especialmente para esse fim $^{3}$ revelaram que em certas populações da fndia $50 \%$ dos sintomáticos respiratórios não procuram recursos médicos para os seus males. Descontando-se o possivel excesso das nossas estimativas persiste a suspeita de que esses sintomas respiratórios talvez não sejam motivo suficiente de preocupação para as pessoas da comunidade em pauta, onde são abundantes os recursos assistenciais previdenciários e particulares. (Ainda que $74 \%$ dos doentes tenham procurado a unidade pressionados pelos sintomas - Tabela 7). Seria interessante pesquisar nesse sentido antes de se planejar o componente educativo de um programa anti-tuberculose alicerçado em cadastro bacteriológico.

Detalhe importante a ser analisado é a ocorrência de falsos assintomáticos porque entre eles a incidência de casos chegou a $10 \%$, representando $26 \%$ dos ca- 
ARANTES, G. R. \& TRIVELLATO, L. B. - Cadastramento bacteriológico antituberculose: estudo preliminar para sua implantação em uma comunidade do Estado de São Paulo (Brasil). Rev. Saúde pübl., S. Paulo, 10:167-76, 1976.

sos diagnosticados! Esse fato parece estar ligado à idade e categoria de matrícula. manifestando-se mais intensamente na categoria "certificados" (Tahela 4). Seria omissão deliberada provocada pelo temor de não receber o documento legal que lhes atesta a aptidão para o trabatho? Falta de preocupação quanto aos sintomas em pauta? Ambas as hipóteses são plausíveis e sugerem a necessidade de estudos sociológicos e medidas educativas a respeito.

Embora seja desejável o exame de todos os sintomáticos que afluem aos serviços de saúde seriam prioritários apenas aqueles com sintomas pelo menos há duas ${ }^{\text {? }}$ ou quatro ${ }^{y}$ semanas; entre eles se encontraria a maior parcela dos casos bacteriologicamente positivos. No presente material não houve correlação entre a duração dos sintomas e a incidência de casos (Tahela 7); ou com o grau de positividade das baciloscopias (Tabela 8). É possivel que os sintomas estivessem presentes por tempos diferentes dos referidos decorrendo os erros da rapidez do interrogatório em regime de atendimento maciço. $\mathrm{Os}$ dados apresentados na Tabela 6 parecem corroborar essa hipótese: nas 3 categorias de matrícula os sintomáticos, há mais de 60 dias, mostraram proporção elevada relativamente àqueles com duração entre 15 a 30 e 30 a 60 dias; o lógico seria um gradiente em declínio, da menor para a maior duração.

Por conseguinte, na prática a duração dos sintomas não deve ser levada em conta ao se definir operacionalmente os sintomáticos.

O grupo etário mais jovem (15 a 19 anos) participou com $31 \%$ da demanda. Apresentando apenas $1,8 \%$ de sintomáti$\cos$ respiratórios e baixa incidência de casos $(0,6$ por 1.000) poderia ficar fora do cadastramento? Contribuindo com $10 \%$ dos casos descobertos seria imprudência deixar de procurar a doença entre eles.
Similarmente, apesar da baixa prevalência de sintomáticos entre os "certificados" (apenas $1.8 \%$ ) e da pequena incidência de casos $(0,15$ por 1.000$), 7 \%$ dos mesmos foram encontrados nessa categoria (todos falsos assintomáticos). Nas localidades sem equipamento abreugráfico um modo de evitar que os mesmos escapem ao diagnóstico seria a pré-seleção tuberculínica dos reatores entre os quais a incidência de casos foi 70 vezes maior (Tabela 11).

Finalmente. há que considerar a utilização da cultura de escarro.

Em regióes onde a tuberculose tem sido descoberta em estágios avançados a proporção de casos positivos somente à cultura é pequena e por isso o benefício adicional com o uso desse exame seria mínimo. A proporção observada de $35 \%$ de casos desse tipo, situação intermediária entre aquelas observadas na India $(18 \%)$ e na Inglaterra $(65 \%)$ s sugere que, havendo meios, esse exame deve fazer parte do cadastramento bacteriológico na região em foco.

\section{CONCLUSOES}

O cadastramento bacteriológico foi bem aceito pela população estudada, porém, a elavada ocorrência de falsos assintomáticos demonstra a necessidade de medidas educativas antecedendo à sua implantação.

A prevalência estimada de adultos com sintomas respiratórios deve ser no minimo de $4,3 \%$ na comunidade em pauta.

A incidência de casos entre os sintomáticos examinados foi de 5,3\%; entre os consultantes sintomáticos chegou a $7,3 \%$.

A ocorrência de $35 \%$ de casos positivos apenas à cultura recomenda o uso desse método quando disponivel. 
ARANTES. G. R. \& TRIVELLATO, L B. - Cadastramento bacteriológico antituberculose: estudo preliminar para sua implantacão em uma comunidade do Estado de São Paulo (Bras1l). Rev. Sulude publ., S. Paulo. 10:167-76. 1976.

\section{RSPU-B/310}

Arantes, G. R. \& Trivellato, L. B. - - T Tuberculosis case-finding by bacteriolgy: a prelminary study for its application in a community in the state of S. Paulo, Brazil], Rev. Saúde públ., S. Paulo, 10:167-76, 1976.

Summary: This study was designed in order to acquire knowledge as regards some characteristics of the population before using sputum examination in case-finding of tuberculous patients. The population studied consisted of 30.885 persons aged 15 and over, registered at the Public Health Center of Ribeirão Preto, SP (Brazil), during 12 consecutive months. People accepted the bacteriologic screening although many symptomatic persons failed to report this condition (false nonsymptomatics). The incidence of cases anong symptomatic persons was $5.3 \%$ and $35 \%$ of all cases were culture-positive only. It was estimated that the prevalence of persons with respiratory symptoms in that community was at least $4.3 \%$.

UNITERMS: Bacteriologic case-finding. Symptomatic persons. False nonsymptomatics.

\section{REFERENCIAS BIBLIOGRÁFICAS}

1 ARANTES. G. R. - Contribuacion para a integraçăo das atividades antituberculose nas undades santarias do Estado de Sĩo Paulo. São Paulo. 1972 [Monografia de mestrado Faculdade de Saúde Pública da [SP].

2. ARANTES, G. R. et al - Interpretação da sensibilidade tuberculinica em populaşão do interior do Estado de São Paulo [Apresentado ao XVII Congresso Nacional de $\mathrm{Tu}$ berculose e Doenças Respiratórias. Brasillia, DF, 19751.

3. BANERJI, D. \& ANDERSEN, $S$ - A sociological study of awareness of symptoms among persons with pulmonary tuberculosis. Bull. Wld. Hlth. org., 29:665-83, 1963

4. CAMPANHA NACIONAI CONTRA A TL'Berculose. Comissão Técnica A bacteriologia na luta contra it tuberculose Rev. Sorv. nac. Tuberc. 11):385-92, 1966.

5. CAMPANiHA NaCIONAL CONTRA A trbercilose. Comissão Téunicia.
Prova tuberculinica em saúde pública (2,a recomendação). Rev. Sert. nac. Tuberc, 12:219-30, 1968

6. FLNDAÇAO IBGE - Sinopse preliminar do censo demográfico: São Paulo Rio de Janeiro, 1971. (VIII Recenseamento Geral, 1970).

7. GRellety-Bosviel, $P$ - De l'importance de standardiser les techniques et lequipement. Bull. int. In. Tuberc, 43:79-86, 1970.

8. MITCHISON, D. A. - Examination of sputum by smear and culture in rase-finding. Bull. int. Un. Tuberc.. 41:135, 1968 .

9. PIO. A. - Normas técnicas y admınistrativas para elaborar y implementar programas de tuberculosis. Washington, DC. Organización Panamericana de la Salud. (Documento $\mathrm{CD} / \mathrm{TB} / 5$ ).

11). SAO PALlO (Estado). Secretaria da Saúde Reforma administrativa: ... letanea de textos legais e regulamerntares. Sāo Paulo, 1971. 
ARANTES, G R. \& TRIVELl.ATO, L. B. - Cadastramento bacteriológico antituberculose: estudo preliminar para sua implantacão em uma comunidade do Estado de São Paulo (Brasil). Rev. Saúde pribl, S Paulo, 10:167-76, 1976.

11. TRIVELlato, L. B. \& COSTA, A. Avaliação da infiuência do método de coleta de amostras de escarro na bacteriologia de b.a.a.r., quando tratadas com trifosfato de sódjo a 14 r piv. Blológrca, Ribeirão Preto. $1: 7-11,1965$.
12. VECCHIO, T. J. - Predictive value of a single diagnostic test in unselected populations. NeU Engl. $J$. Med., ? it:1171-3. 1966

Recebido para publicasão em 03/12/1975 Aprovado para publicasio em 05/01/1976 